\begin{tabular}{|l|l|l||}
\hline \multicolumn{2}{|c|}{ PublisherInfo } \\
\hline \hline PublisherName & $:$ & BioMed Central \\
\hline \hline PublisherLocation & $:$ & London \\
\hline \hline PublisherImprintName & $:$ & BioMed Central \\
\hline \hline
\end{tabular}

\title{
Community-based study highlights sex differential in post-MI mortality
}

\begin{tabular}{||l|l|l||}
\hline \multicolumn{2}{|c||}{ ArticleInfo } \\
\hline \hline ArticleID & $:$ & 42 \\
\hline \hline ArticleDOI & $:$ & $10.1186 /$ cvm-2001-72056 \\
\hline \hline ArticleCitationID & $:$ & 72056 \\
\hline \hline ArticleSequenceNumber & $:$ & 21 \\
\hline \hline ArticleCategory & $:$ & Paper Report \\
\hline ArticleFirstPage & $:$ & 1 \\
\hline \hline ArticleLastPage & $:$ & 3 \\
\hline \hline & & RegistrationDate : 2001-10-18 \\
ArticleHistory & $:$ & Received $\quad: 2001-3-14$ \\
& & OnlineDate $\quad$ 2001-10-18 \\
\hline \hline ArticleCopyright & $:$ & Biomed Central Ltd2001 \\
\hline \hline
\end{tabular}




\begin{tabular}{|l|l|l||}
\hline ArticleGrants & $:$ & \\
\hline \hline ArticleContext & $:$ & 1306322 \\
\hline
\end{tabular}

Joanna Lyford, ${ }^{\text {Aff1 }}$

Corresponding Affiliation: Aff1

Aff1 MedWire, UK

Keywords

Age factors, myocardial infarction, outcome assessment (health care), patient discharge, sex factors

\section{Context}

This study examined whether younger women have a worse long-term prognosis after suffering a myocardial infarcton (MI) than men.

\section{Significant findings}

At baseline (hospital discharge) there were sex-related differences: women were significantly older ( 71.4 versus 63.2 years; $P<0.001)$ and were more likely to have a history of heart failure and hypertension. Men were more likely to have a history of MI and experience arrhythmias and Q-wave infarction, while women suffered more heart failure and heart block. By 2 years after discharge, 1,577 patients had died ( $28.9 \%$ of the women versus $19.6 \%$ of men); this translated into a hazard ratio for women of 1.47 (95\% confidence interval [CI] 1.35-1.61). However, further analysis revealed that this increased risk was only applicable to younger women ( $<60$ years), with older ( $>60$ years) women having a similar prognosis to older men. Sex differences in mortality rate decreased with advancing age, and, among the oldest patients, women tended to have lower mortality rates than men. Results were consistent when examined in terms of risk difference. The absolute risk for women compared with men was highest in patients younger than 60 years of age, while the absolute risk was lower for women among patients at least 80 years of age.

When the authors adjusted for age in a Cox proportional hazards model, it seemed to explain the overall sex difference in 2 year mortality rate, yielding a hazard ratio of 1.00 (95\% CI $0.90-1.12$ ). However, when the interaction between sex and age was included in the model, it was found to be 
statistically significant. For every 10 -year decrease in patients' age, hazards of death in women increased $13.1 \%$ (95\% CI 3.1\%-23.9\%) compared with men. When the multivariable-adjusted results were expressed in terms of absolute risk difference, an increased mortality rate among women compared with men was found only among patients younger than 60 years of age. Among older patients, women had a lower absolute risk for death than men.

\section{Comments}

The reasons for the sex differential remain unclear. The most likely are genetic, hormonal, or inflammatory factors. An accompanying editorial (see Additional information) points out that, although endogenous estrogens are known to be cardioprotective, some studies have shown increased levels of Creactive protein with exogenous hormone therapy, suggesting that this common treatment used primarily by middle-aged women has potential pro-inflammatory effects. The editorial concludes: 'While researchers strive to confirm the age-sex interaction and to understand its mechanisms, practicing physicians can ensure that interventions of proven value, including effective cardiac drugs, antidepressants, smoking cessation, and cardiac rehabilitation, are consistently provided to all eligible patients after myocardial infarction.'

\section{Methods}

The authors designed a community-based prospective cohort study that included 6826 survivors of acute MI.

\section{Additional information}

Ayanian JZ: Increased mortality among middle-aged women after myocardial infarction: searching for mechanisms and solutions. Ann Intern Med 2001, 134:239-241. 


\section{References}

1. Vaccarino V, Krumholz HM, Yarzebski J, Gore JM, Goldberg RJ: Sex Differences in 2-Year Mortality after Hospital Discharge for Myocardial Infarction . Ann Intern Med. 2001, 134: 173-181.

This PDF file was created after publication. 